\title{
O PRINCÍPIO DA SEGURANÇA JURÍDICA EM FACE DA COISA JULGADA INCONSTITUCIONAL*
}

\author{
EL PRINCIPIO DE LA SEGURIDAD JURÍDICA \\ ANTE LA COSA JUZGADA INCONSTITUCIONAL \\ THE PRINCIPLE OF LEGAL SECURITY IN FACE \\ OF UNCONSTITUTIONAL STARE DECISIS
}

Maria Elizabeth Guimarães Teixeira RochA**

Data de recepção: 23 de julho de 2015 Data de aceitação: 6 de novembro de 2015 Disponivel on-line: 30 de novembro de 2015

\section{PARA CITAR este ARTigo / PARA CITAR}

ESTE ARTÍCULO / TO CITE THIS ARTICLE

Rocha, Maria Elizabeth Guimarães Teixeira, O princípio da segurança jurídica em face da coisa julgada inconstitucional, 27 International Law, Revista Colombiana de Derecho Internacional, 39-64 (2015). http://dx.doi. org/10.11144/Javeriana.i115-27.opsj

doi:10.11144/Javeriana.i115-27.opsj

* Artigo de reflexão.

** Doutora em Direito Constitucional, Universidade Federal de Minas Gerais, UFMG. Mestra em ciências jurídico-políticas, Universidade Católica Portuguesa, UCP. Professora Universitária do Centro de Ensino Unificado de Brasília, CEUB. Ministra do Superior Tribunal Militar do Brasil, STM. Contato: minelizabethrocha@stm.jus.br 


\section{RESUMO}

Valorações jurídicas sobre a coisa julgada inconstitucional constituem um desafio para a Ciência do Direito. O tema descortina a impossibilidade da permanência da res iudicata desconforme com a Lei Maior do Estado e o impasse que, eventualmente, poderá advir diante do postulado da segurança jurídica. De fato, impugnável a decisão judicial transitada em julgado, formal ou materialmente, se o conteúdo se opuserà Carta Política da Nação. No Brasil, o artigo 5, inciso XXXVIda Constituição Federal, reveste-a de intangibilidade tão somente no tocante à retroação da lei infraconstitucional no tempo que, porventura, possa modificar ou rechaçar direito já assegurado sob o pálio de norma anterior pelo Poder Judiciário. Sem embargo, se ela esbater-se em preceito magno, preveem tanto o Código Processual Civil quanto Penal Brasileiro, mecanismos para desconstituí-la e, consequentemente, findar seus efeitos. O presente artigo traz a lume doutrina que maneja o tema, bem como pontua os instrumentos disponíveis na processualística pátria para atacar a imutabilidade da coisa julgada inquinada pelo vício da pior das nulidades absolutas: a inconstitucionalidade. Nesse diapasão, destaca os dispositivos legais que regem a matéria e a jurisprudência das Cortes Superiores nacionais para, ao final, concluir pela submissão de todos os atos estatais - executivos, legislativos ou judiciais- estes últimos, inclusive, com o trânsito em julgado já operado, à aferição do controle de constitucionalidade em sede incidental. Proclamada a sua incompatibilidade vertical em face da Lex Magna, deverá a res iudicata ser nulificada e operar efeitos ex tunc, como única maneira de assegurar a força normativa da Constituição.

Palavras-chave: Coisa julgada; inconstitucionalidade; segurança jurídica; Poder Judiciário; controle de constitucionalidade

\section{RESUMEN}

Las valoraciones jurídicas sobre la cosa juzgada inconstitucional constituyen un reto para la Ciencia del Derecho. El tema revela la imposibilidad de que la res judicata permanezca en desacuerdo con la Ley Suprema del Estado y el callejón sin salida que, eventualmente, podría provenir frente al postulado de seguridad jurídica. De hecho, es impugnable la decisión judicial transitada en juzgado, formal o materialmente, si el contenido se opone a la Carta Politica de la Nación. En Brasil, el artículo 5, inciso XXXVI de la Constitución Federal, la reviste de intangibilidad tan sólo en lo referente a la retroacción de la ley infraconstitucional en el tiempo que, por ventura, pudiera modificar o rechazar el derecho ya asegurado bajo el escudo de la norma anterior por el Poder Judicial. Sin embargo, si esta se atenúa en precepto magno, tanto el Código de Procedimiento Civil como el Penal Brasileño prevén mecanismos para deshacerla y, consecuentemente, poner fin a sus efectos. El presente artículo trae la doctrina luz que maneja el tema, así como puntualiza los instrumentos disponibles en el procesalismo patrio para atacar la inmutabilidad de la cosa juzgada viciada por 
la peor de las nulidades absolutas: la inconstitucionalidad. En ese orden de ideas, se destacan los dispositivos legales que rigen la materia y la jurisprudencia de las Cortes Superiores nacionales para, finalmente, concluir sometiendo todos los actos estatales - ejecutivos, legislativos o judiciales, incluso estos últimos con el tránsito en juzgado ya operado-, a la medición del control de constitucionalidad en sede incidental. Proclamada su incompatibilidad vertical de cara a la Lex Magna, la res judicata deberá ser anulada y aplicársele los efectos ex tunc, como única manera de asegurar la fuerza normativa de la Constitución.

Palabras clave: Cosa juzgada; inconstitucionalidad; seguridad jurídica; Poder Judicial; control de constitucionalidad

\section{ABSTRACT}

The legalassessment about the unconstitutional stare decisis is a challengefor The Science of Law. The theme reveals the impossibility of the res iudicata, formal or material, opposes against the Federal Constitution and the difficulties that may eventually come due the principle of legal security and Court surety. Indeed, it is possible in legal terms challenge the judicial decision which conflicts with the State's highest law. In Brazil, Article 5, XXXVI of the Federal Constitution only protects the intangibility of stare decisis with regard of retroactivity of law which could be review or even reversal individual rights. Nevertheless, if a judicial sentence eroded a constitutional precept, the Brazilian Criminal Procedure Code as also the Code of Civil Procedure, predicts mechanisms to nullify decisions guaranteed by a pronouncement by the Judiciary Power and ends its effects. This article presents the doctrine about this juridical discussion as well as evaluates the available instruments in Comparative Law to attack the immutability of res iudicata contaminated by the worst nullity: the unconstitutionality. In this vein, this text will highlight the jurisprudence of National High Courts to conclude the necessary submission of all state acts —executive, legislative or judicialto the Constitution, including the stare decisis, which judgments has already been definitively decided and the issue cannot be litigated again. Proclaimed the vertical incompatibility in the face of Lex Magna, the stare decisis must be nullified and operate ex tunc effects as the only way to ensure the normative force of the Constitution.

Keywords: Unconstitutional; stare decisis; legal security; Judiciary Power; judicial review

\section{SUMÁRIO}

Introdução.- I. A coisa julgada inconstitucional.- II. Mecanismos ProCESSUAIS PARA DESCONSTITUIR A COISA JULGADA INCONSTITUCIONAL No DiREITO Brasileiro.- $A$. A ação rescisória.- $B$. A querella nulitatis insanabilis.- $C$. As ações cautelares.- D. A revisão criminal.- Conclusão.- Bibliografia. 
INTRODUÇÃO

A contextualização propedêutica da coisa julgada inconstitucional reflete a nova hermenêutica no sistema contemporâneo de controle de constitucionalidade, tendo a teoria esbatido-se sobre a necessidade de problematizar a inarmonia axiológica consolidada nos atos jurisdicionais em face da Lex Magna.

O tema traz a lume questão que merece percuciente debate por sua relevância. Discute-se a prevalência da sententia judicis revestida de imutabilidade desconforme com a Constituição, $\mathrm{CF}$.

Diversas análises acadêmicas e jurisprudenciais cotejam os princípios da segurança jurídica e da justiça no campo do Direito, correlacionando-os com a efetividade do processo. Nessa perspectiva, impõe-se o exame da res judicata detentora de caráter inconciliável com a Lei Maior e, por decorrência, eivada de nulidade, com suporte nas decisões judiciais e na doutrina.

Consabido que os atos emanados pelos Poderes do Estado Executivo, Legislativo e Judiciário-devem, obrigatoriamente, coadunar-se com a Carta Política, sob pena de incorrerem em invalidação. $\mathrm{O}$ acatamento aos postulados máximos respalda e sustenta o Estado Democrático.

Ensina Jorge Miranda:

Na Constituição se plasma um determinado sistema de valores da vida pública, dos quais é indissociável. Um conjunto de princípios filosóficojurídicos e filosófico-políticos vêm-na justificar e vêm-na criar ${ }^{1}$.

Nesse sentido,

sendo certo que as decisões jurisdicionais configuram atos jurídicos estatais, posto reproduzir a manifestação da vontade do Estado, sua validade pressupõe estejam elas em consonância com os ditames constitucionais. Por esse motivo, não se pode convalidar sua inconstitucionalidade, visto ser improvável abrir mão de mecanismos susceptíveis de permitir a efetivação

1 Jorge Miranda, Contributo para uma teoria da inconstitucionalidade, 30 (Coimbra Editora, Coimbra, 1999). 
de modificações imprescindíveis ao seu ajustamento aos cânones do direito constitucional. (...)

O Poder Judiciário não detém a soberania e, como tal, não se pode justificar o mito da intangibilidade da função jurisdicional, enquanto manifestação do exercício da atividade estatal. (...)

O exercício da função jurisdicional tem amparo no 'modelo constitucional do processo civil', instrumentalizado por normas e princípios que balizam seu procedimento formal, cujo paradigma central tem o magistrado como figura de relevo a dizer o direito ${ }^{2}$.

\section{A COISA JULGADA INCONSTITUCIONAL}

A concepção de coisa julgada, em tempos antigos, era impregnada com outra percepção. Para Enrico Túlio Liebman:

A coisa julgada era vista como a imposição da declaração de verdade contida na sentença. A partir daí não foi difícil conceber-se a coisa julgada como ficção de verdade, como verdade formal ou presunção de verdade. Esta fórmula teve intensa difusão, tendo sido defendida por [Friedrich Karl von] Savigny e [Robert Joseph] Pothier, mas hoje estão definitivamente superadas ${ }^{3}$.

Conceitualmente, a res judicata formal consiste na inimpugnabilidade da sentença no processo em que foi proferida. A respeito do instituto, esclarece Nelson Nery Júnior:

Ocorre a coisa julgada formal quando a sentença não mais está sujeita a recurso ordinário ou extraordinário, quer porque dela não se recorreu; quer porque se recorreu em desacordo com os requisitos de admissibilidade dos recursos ou com os princípios fundamentais dos recursos; quer, ainda, porque foram esgotados todos os meios recursais de que dispunham as partes e interessados naquele processo. Para a coisa julgada formal leva-se em conta, principalmente, a inimpugnabilidade da sentença, vale dizer, o momento em que se forma a coisa julgada. A denominação coisa julgada formal é equívoca, mas se encontra consagrada na doutrina. Trata-se, na verdade, de preclusão e não de coisa julgada. Não é objeto da garantia

2 Carlos Valder do Nascimento, Coisa julgada inconstitucional, em Coisa julgada inconstitucional, 3-5 ( $2^{\mathrm{a}}$ ed. ver. e ampl., Carlos Valder do Nascimento, coord., América Jurídica, Rio de Janeiro, 2003).

3 Enrico Túlio Liebman, Manual de direito processual civil, 15-16 (Forense, Rio de Janeiro, 1984). 
constitucional da CF 5, XXXVI [a lei não prejudicará o direito adquirido, o ato jurídico perfeito e a coisa julgada], que abrange apenas a autoridade da coisa julgada (coisa julgada material) ${ }^{4}$ (sem letra negrita no original).

\section{A título de comparação, os autores conceituam a coisa julgada material (auctoritas rei iudicatae) como:}

a qualidade que torna imutável e indiscutível o comando que emerge da parte dispositiva da sentença de mérito não mais sujeita a recurso ordinário ou extraordinário (CPC 467; LICC $\left.6^{\circ}, \S 3^{\circ}\right)$, nem à remessa necessária do CPC 475 (...). Somente ocorre se e quando a sentença de mérito tiver sido alcançada pela preclusão, isto é, a coisa julgada formal é pressuposto para que ocorra a coisa julgada material (...), mas não o contrário. A coisa julgada material é um efeito especial da sentença transitada formalmente em julgado (...). A característica essencial da coisa julgada material se encontra na imutabilidade da sentença, que não se confunde com sua eficácia (... $)^{5}$.

4 Nelson Nery Jr. \& Rosa Maria de Andrade Nery, Código de processo civil comentado e legislação extravagante, 682-683 (10 $\mathrm{ed}$. ver. ampl. e atual., Editora Revista dos Tribunais, RT, São Paulo, 2008). Brasil, Constituição da República Federativa do Brasil, CF, Brasília, 5 de outubro de 1988. Disponível em: http://www.planalto.gov.br/ccivil_03/Constituicao/ Constituicao.htm

5 Nelson Nery Jr. \& Rosa Maria de Andrade Nery, Código de processo civil comentado e legislação extravagante, $680\left(10^{\mathrm{a}}\right.$ ed. ver. ampl. e atual., Editora Revista dos Tribunais, RT, São Paulo, 2008). Artigo 467, CPC: "Denomina-se coisa julgada material a eficácia, que torna imutável e indiscutível a sentença, não mais sujeita a recurso ordinário ou extraordinário". Brasil, Lei 5.869, 11 de janeiro de 1973, institui o Código de Processo Civil, CPC, Diário Oficial da União, DOU, 17 de janeiro de 1973 e republicado em 27 de julho de 2006. Disponível em: http://www.planalto.gov.br/ccivil_03/LEIS/L5869compilada.htm. Artigo 6, §3, LICC: "A Lei em vigor terá efeito imediato e geral, respeitados o ato jurídico perfeito, o direito adquirido e a coisa julgada. Chama-se coisa julgada ou caso julgado a decisão judicial de que já não caiba recurso". Brasil, Decreto-Lei 4.657, de 1942, Lei de Introdução às normas do Direito Brasileiro (ao Código Civil), LICC, Diário Oficial da União, DOU, 4 de setembro de 1942. Disponível em: http://www.planalto.gov.br/ccivil_03/ Decreto-Lei/Del4707.htm. Artigo 475, CPC: "Está sujeita ao duplo grau de jurisdição, não produzindo efeito senão depois de confirmada pelo tribunal, a sentença: proferida contra a União, o Estado, o Distrito Federal, o Município, e as respectivas autarquias e fundações de direito público; que julgar procedentes, no todo ou em parte, os embargos à execução de dívida ativa da Fazenda Pública (art. 585, VI). Nos casos previstos neste artigo, o juiz ordenará a remessa dos autos ao tribunal, haja ou não apelação; não o fazendo, deverá o presidente do tribunal avocá-los. Não se aplica o disposto neste artigo sempre que a condenação, ou o direito controvertido, for de valor certo não excedente a 60 (sessenta) salários mínimos, bem como no caso de procedência dos embargos do devedor na execução de dívida ativa do mesmo valor. Também não se aplica o disposto neste artigo quando a sentença estiver fundada em jurisprudência do plenário do Supremo Tribunal Federal ou em súmula deste Tribunal ou do tribunal superior competente". 
Do exposto, a lei processual reveste de imutabilidade quaestio já decidida nos limites da lide proposta, conferindo-lhe o trânsito em julgado formal e, a posteriori, material ${ }^{6}$.

De singular importância, a coisa julgada material impede a propositura de ação já intentada, assim considerada aquela que contêm idênticos elementos, quais sejam; as mesmas partes, a mesma causa de pedir próxima (fundamentos de fato) e remota (fundamentos de direito) e o mesmo pedido (mediato e imediato), da anteriormente interposta e decidida.

O momento de sua consolidação ocorre tão logo ultrapassada a fase recursal, quer pela inexistência de recurso, quer por ter sido ele declarado intempestivo, quer, ainda, por terem se esgotado todos os meios processuais de impugnação. A partir daí, a decisão não mais é atacável.

Inolvidável, porém, revestir-se dita intangibilidade da necessária submissão à Constituição. Estratificada, deve a res judicata ${ }^{7}$, restar coberta pelas determinações da Lei Fundamental, do contrário, eventuais vícios de conformação hierárquico-jurídico deverão ser discutidos em recurso ou ação própria para refutá-la.

A questão fulcral centra-se na implementação do direito justo ${ }^{8}$ e sua necessária adequação à voluntas legislatoris do Colégio

6 Elucida Pontes de Miranda: "a irrecorribilidade pela natureza especial da sentença, ou pela preclusão, é que faz julgada a res judicata". Pontes de Miranda, Comentários ao Código de Processo Civil, tomo V, 111 ( $3^{\mathrm{a}}$ ed., Forense, Rio de Janeiro, 1997). A seu turno, Eduardo Espínola define-a: "A compreensão generalizada, na doutrina pátria, é que se considera caso julgado a sententia judicis, de que não caiba recurso algum. Daí a distinção entre sentença passada em julgado e coisa julgada, ou caso julgado; a sentença se diz que passou em julgado, quando pode ser executada, embora seja ainda suscetível de reforma, por virtude de algum recurso; a coisa julgada, ou o caso julgado, só se tem, quando nenhum recurso, absolutamente nenhum, pode haver, que eventualmente leve a modificá-la; seja embora recurso extraordinário ou ação rescisória”. Eduardo Espínola \& Eduardo Espínola Filho, A lei de introdução ao Código Civil brasileiro, $182\left(2^{\mathrm{a}} \mathrm{ed}\right.$., Renovar, Rio de Janeiro, 1995).

7 A definição jurídico-processual de coisa julgada, em latim, res judicata, está disposta no artigo 467, do Código de Processo Civil. Lê-se: "Denomina-se coisa julgada material a eficácia, que torna imutável e indiscutível a sentença, não mais sujeita a recurso ordinário e extraordinário".

8 Em um "Estado de direito material, tal como a lei positiva não é absoluta, também não o são as decisões judiciais. Absoluto, esse sim é sempre o Direito ou, pelo menos, a idéia de um DIREITO JUSTO”. Paulo Manuel Cunha da Costa Otero, Ensaio sobre o caso julgado inconstitucional, 10 (LEX Edições Jurídicas, Lisboa, 1993). Sobre a matéria exprimiu-se o Ministro do Superior Tribunal de Justiça, STJ, José Augusto Delgado: "Há de se ter como certo que a segurança jurídica deve ser imposta. Contudo, essa segurança 
Formal da Soberania. Nesses termos, inadmissível debitar-se imutabilidade à sentença que revela incompatibilidade com o ordenamento superior, a despeito de o trânsito em julgado terse operado. Isso porque o poder judicial detém competência exercível nos quadros da Constituição, não podendo criar decisões sem fundamento direto ou em oposição ao preceituado na Norma Normarum ${ }^{9}$. Por conseguinte, acatar a eficácia da coisa julgada inconstitucional é uma visão processualística que não se coaduna com a orientação inserta no direito constitucional contemporâneo; o julgado é írrito e encontra ressonância na teoria das nulidades"10. Insubsistente, portanto, prolação judicial dissonante com a Carta da República.

Sabido é que a Lex Fundamental não dispensou tratamento ao instituto da res judicata, limitando-se a resguardá-la dos efeitos da lei nova - artigo 5, inciso XXXVI, $\mathrm{CF}^{11}$. O princípio da intangibilidade que a reveste é noção processual, de categoria normativa inferior ${ }^{12}$. Dito de outra forma, "a coisa julgada

jurídica cede quando princípios de maior hierarquia postos no ordenamento jurídico são violados pela sentença (...)". José Augusto Delgado, Efeitos da coisa julgada e os princípios constitucionais, em Coisa julgada inconstitucional, 96-97 ( $2^{\mathrm{a}}$ ed. ver. e ampl., Carlos Valder do Nascimento, coord, América Jurídica, Rio de Janeiro, 2003).

9 Segundo Paulo Otero: "Salvo melhor entendimento, propendemos a considerar que, em termos jurídicos-criminais, a obrigatoriedade de sentenças inconstitucionais traduz um dever jurídico imperfeito. Significa isto que, apesar de tais sentenças serem obrigatórias, em termos gerais, a sua inexecução não pode gerar responsabilidade criminal (...). Por outras palavras, verificando-se a inexecução de uma sentença inconstitucional, entendemos que essa mesma inconstitucionalidade consubstancia uma causa especial de justificação ou de exclusão da ilicitude de um comportamento que em circunstâncias diferentes seria configurável como ilícito criminal de resistência e desobediência à autoridade pública. Com efeito, insistimos, o princípio geral aplicável à inexecução das sentenças inconstitucionais deve ser o seguinte: ninguém pode ser responsabilizado criminalmente pelo incumprimento de atos inconstitucionais, sob pena de o Estado de Direito democrático se fundar na repressão criminal de comportamentos desconformes com os valores e preceitos constitucionais. Admitir solução contrária significaria uma verdadeira ruptura ou quebra da adequação valorativa e da unidade interna de ordem jurídica aos princípios fundamentais da Constituição". Paulo Manuel Cunha da Costa Otero, Ensaio sobre o caso julgado inconstitucional, 166 (LEX Edições Jurídicas, Lisboa, 1993).

10 Carlos Valder do Nascimento, Por uma teoria da coisa julgada inconstitucional, 107 (Lumen Juris, Rio de Janeiro, 2005).

11 Estatui o artigo 5, inciso XXXVI, da Constituição Federal que: "a lei não prejudicará o direito adquirido, o ato jurídico perfeito e a coisa julgada".

12 Humberto Theodoro Jr. \& Juliana Cordeiro de Faria, A coisa julgada inconstitucional e os instrumentos processuais para o seu controle, em Coisa julgada inconstitucional, $141\left(2^{\mathrm{a}}\right.$ ed. ver. e ampl., Carlos Valder do Nascimento, coord., América Jurídica, Rio de Janeiro, 2003). 


\section{é fenômeno processual, de que trata a lei infraconstitucional, e de que a Constituição Federal se ocupa só para fixar o que se deve entender por irretroatividade da lei"13.}

Assim, à parte prejudicada pela nulidade absoluta, ipso iure, não poderá a Justiça negar acesso à respectiva declaração de invalidade do julgado ${ }^{14}$.

Destaca Piero Calamandrei:

La verdad es que ninguna legislación, ni siquiera las dominadas por el principio germánico de la validez formal de la sentencia, ni tampoco las modernamente inspiradas en la aceleración del término de la litis y en alcanzar con mayor rapidez la certeza sobre el fallo, pueden sustraerse a las leyes de la razón y de la lógica; y en obediencia a estas, debe la ciencia admitir, aunque sea en la medida más restringida, que aun después de la preclusión de los medios de impugnación, subsistan sentencias afectadas por la nulidad insanable ${ }^{15}$.

13 Teresa Arruda Alvim Wambier \& José Miguel Garcia Medina, O dogma da coisa julgada: hipóteses de relativização, 172 (Editora Revista dos Tribunais, RT, São Paulo, 2003). Na lição de Teresa Arruda Alvim e José Miguel Garcia Medina: “(...) é importante observar-se que a Constituição Federal protege da incidência da nova lei decisão que se tenha baseado em lei anterior e que, sob a égide desta, tenha transitado em julgado. Por isso é que se pode dizer que a proteção à coisa julgada é uma destas facetas do princípio da irretroatividade da lei. (...) Não se deve, portanto, superestimar a proteção constitucional à coisa julgada, tendo-se sempre presente que o texto protege a situação concreta da decisão transitada em julgado contra a possibilidade de incidência de nova lei. Não se trata de proteção ao instituto da coisa julgada (em tese) de molde a torná-lo inatingível, mas de resguardo de situações em que se operou a coisa julgada, da aplicabilidade de lei superveniente. (...)". Teresa Arruda Alvim Wambier \& José Miguel Garcia Medina, $O$ dogma da coisa julgada: hipóteses de relativização, 170-171 (Editora Revista dos Tribunais, RT, São Paulo, 2003).

14 Na lição de Renato Alessi: "La prima peculiarità si ricollega al fatto che l'amministrazione, appunto in quanto representa in concreto lo Stato, deve necessariamente participare della posizione giuridica e dei potere di questo. Pertanto anche la pubblica amministrazione normalmente, si presenta come titolare di quell potere d'impero che rappresenta la caracteristica essenziale della posizione, pertanto, normalmente compete il potere di far prevalere coattivamente la sua volontà su quella dei privatti individui, nel che, sostanzialmente, si concreta appunto il potere d'impero". Renato Alessi, Sistema instituzionale del diritto amministratìvo italiano, 148 (Giuffrè, Milano, 1953).

15 Piero Calamandrei, Vicios de la sentencia y medios de gravamen, em Estudios sobre el proceso civil, 463 (Ediciones Jurídicas Europa-América, EJEA, Buenos Aires, 1961). 


\section{MECANISMOS PROCESSUAIS PARA DESCONSTITUIR A COISA JULGADA INCONSTITUCIONAL NO DIREITO BRASILEIRO}

\section{A. A ação rescisória}

Prevê o Códex Adjetivo Cível a ação rescisória, a ação declaratória de inexistência de relação jurídica, a antiga querella nullitatis de rito ordinário e que independe de prazo, e os instrumentos processuais acautelatórios, a saber; a medida cautelar e a suspensão de segurança para sobrestar a execução do julgado, como mecanismos obstaculizadores dos efeitos concretizantes da res judicata.

Chama-se rescisória, na lição de José Carlos Barbosa Moreira, a "ação por meio da qual se pede a desconstituição de sentença trânsita em julgado, com eventual rejulgamento, a seguir, da matéria nela julgada. O direito brasileiro, à semelhança de outros ordenamentos, conhece dois tipos de remédios utilizáveis contra decisões judiciais: os recursos e as ações autônomas de impugnação. Em nosso sistema, o traço distintivo consiste em que, através de recurso, se impugna a decisão no próprio processo em que foi proferida, ao passo que o exercício de ação autônoma de impugnação dá sempre lugar à instauração de outro processo. A ação rescisória é o exemplo clássico dessa segunda espécie"16.

Da leitura do artigo 485 do Código de Processo Civil ${ }^{17}$, depreende-se ser a ação rescisória o remédio jurídico-processual

16 José Carlos Barbosa Moreira, org., Comentários ao Código de Processo Civil, vol. 5, 100 (10 a ed., Forense, Rio de Janeiro, 2002).

17 Litteris: "Art. 485. A sentença de mérito, transitada em julgado, pode ser rescindida quando: I. for proferida por juiz impedido ou absolutamente incompetente; II. resultar de dolo da parte vencedora em detrimento da parte vencida, ou de colusão entre as partes, a fim de fraudar a lei; III. ofender a coisa julgada; IV. violar literal disposição de lei; V. se fundar em prova, cuja falsidade tenha sido apurada em processo criminal ou seja provada na própria ação rescisória; VI. depois da sentença, o autor obtiver documento novo, cuja existência ignorava, ou de que não pôde fazer uso, capaz, por si só, de lhe assegurar pronunciamento favorável; VII. houver fundamento para invalidar confissão, desistência ou transação, em que se baseou a sentença; VIII. fundada em erro de fato, resultante de atos ou de documentos da causa". Brasil, Lei 5.869, 11 de janeiro de 1973, institui o Código de Processo Civil, CPC, Diário Oficial da União, DOU, 17 de janeiro de 1973 e republicado em 27 de julho de 2006. Disponível em: http://www.planalto.gov. br/ccivil_03/LEIS/L5869compilada.htm 
para desconstituir o decisum que não mais poderá ser atacado pela via recursal. Trata-se de ação autônoma, que não só enseja novo processo subsequente àquele onde foi proferida a decisão, como pressupõe seu encerramento definitivo. Por outras palavras, a ação dá origem à nova relação processual diversa daquela onde fora prolatada a sentença ou o acórdão que se busca rescindir ${ }^{18}$.

Sua natureza jurídica é de ação constitutiva negativa ou desconstitutiva dos efeitos materiais da resolução de mérito operada em julgado, devido à ocorrência de alguns dos vícios previstos no dispositivo legal ${ }^{19}$. Saliente-se o inciso IV, que dita como pressuposto de admissibilidade para a propositura da rescisória, violação de literal disposição de lei.

Doutrina e jurisprudência não divergem quanto à abrangência a ser conferida à expressão "lei", tomada na mais ampla acepção. Sinônimo de "norma jurídica", há de ser compreendida em

18 Ovídio Araújo Baptista da Silva, Curso de processo civil: processo de conhecimento, vol.

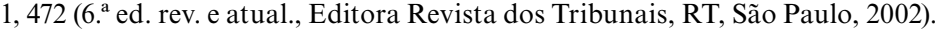

19 A instituição de regras processuais para denunciar errores in procedendo encontra guarida em diversas legislações da Europa. No direito luso, vícios iguais ou assemelhados aos que, na legislação brasileira, fundamentam o cabimento de ação rescisória, são denunciáveis no moderno processo português, por meio do requerimento de revisão, que se inclui no rol dos recursos (Código de Processo Civil, art. 676, 2a alínea), mas que é interponível contra decisão já passada em julgado. No ordenamento francês e italiano, bem como no espanhol, ela corresponde, em parte, ao recurso de cassação, e em parte, respectivamente ao recours en révision (na legislação anterior, ao requête civile), à revocazione e à revisión -que também se incluem, tradicionalmente, entre os recursos, com ressalva da revisión espanhola, deslocada para outro contexto pela nova Ley de enjuiciamiento civil, LEC (arts. 509 e segs.). De igual forma, os ordenamentos austríaco e alemão prevêem além dos recursos (rechtsmittel), a nichtigkeitsklage e a restitutionsklage ou wiederaufnahmsklage, cabíveis contra decisões em processos encerrados; vg: nichtigkeitsklage: ZPO alemã, § 579; ZPO austríaca, § 529; restitutionsklage: ZPO alemã, § 580; wiederaufnahmsklage: ZPO austríaca, § 530. Portugal, Código de Processo Civil, Lei 41/2013, 26 de junho, retificada pela Declaração de Retificação 36/2013, 12 de agosto - Aprova o Código de Processo Civil (revoga o Decreto-Lei 44129, de 28 de dezembro de 1961 / em vigor a partir de 1 de setembro de 2013). Disponível em: http://www.dgpj.mj.pt/sections/leis-da-justica/ livro-iii-leis-civis-e/consolidacao-processo/codigo-de-processo-civil/. França, Code de procédure civile. Disponível em: http://www.legifrance.gouv.fr/affichCode.do?cidTexte= LEGITEXT000006070716. Itália, Codice di procedura civile. Disponível em: http://www. testolegge.com/italia/procedura-civile. Espanha, Ley 1/2000, 7 de enero de 2000, Ley de Enjuiciamiento Civil. Disponível em: https://boe.es/buscar/act.php?id=BOE-A-2000-323. Alemanha, Zivilprozessordnung (Code of Civil Procedure as promulgated on 5 December 2005). Disponível em: http://www.gesetze-im-internet.de/zpo/BJNR005330950.html, http://www.gesetze-im-internet.de/englisch_zpo/englisch_zpo.html. Áustria, Zivilprozessordnung, Gesetz vom 1. August 1895. Disponível em: http://www.wipo.int/wipolex/ es/text.jsp?file_id=230305 
todos os níveis da positividade vigente. Assim, tanto se pode conceber a ação rescisória para impugnar decisão que violou a Constituição quanto as leis propriamente ditas, nelas incluídas as medidas provisórias e os atos infralegais, como decretos e regulamentos.

Na primeira hipótese, está-se diante de coisa julgada inconstitucional, absolutamente nula, passível de desconstituição pela via da rescindibilidade ou de correção por meio da actio nullitatis, referida mais adiante.

Na lição de Teresa Arruda Alvim Wambier e José Miguel Garcia Medina:

Em princípio nos parece que, em linhas gerais, o regime jurídico a que se submete sentença que ofende a Constituição Federal é o da rescindibilidade, idêntico àquele ao qual se submete sentença que ofende a lei (art. 485, inc. $V$, do $C P C)^{20}$.

Por seu turno, o ilustre processualista Humberto Theodoro Júnior e Juliana Cordeiro de Faria pontificam:

Muito embora não haja necessidade de se valer da ação rescisória para obter o reconhecimento do vício sério (nulidade) que contamina a decisão judicial, força é lembrar que "não será correto omitir-se o tribunal de apreciar a questão, se a parte lançar mão da ação do art. 485 do Código de Processo Civil. É que as nulidades ipso iure devem ser conhecidas e declaradas independentemente de procedimento especial para esse fim, $e$ podem sê-lo (...) incidentalmente em qualquer juízo ou grau de jurisdição, até mesmo de ofício segundo o princípio contido no art. 146 e seu parágrafo único do Código Civil ${ }^{21}$.

Nada obsta, então, que a res judicata contra ius constitutionis ou contra legis seja objurgada pela via rescisória.

20 Teresa Arruda Alvim Wambier \& José Miguel Garcia Medina, O dogma da coisa julgada: hipóteses de relativização, 39 (Editora Revista dos Tribunais, RT, São Paulo, 2003).

21 Humberto Theodoro Jr. \& Juliana Cordeiro de Faria, A coisa julgada inconstitucional e os instrumentos processuais para o seu controle, em Coisa julgada inconstitucional, $168\left(2^{\mathrm{a}}\right.$ ed. ver. e ampl., Carlos Valder do Nascimento, coord., América Jurídica, Rio de Janeiro, 2003). 


\section{B. A querella nulitatis insanabilis}

\section{Outro procedimento jurisdicional para a desconstituição de sen- tentia transitada em julgado é a ação declaratória de inexistência de relação jurídica, a querella nullitatis insanabilis, procedimento autônomo, concebido com o escopo de atacar a imutabilidade da res iudicata inquinada pelo vício nulidade ${ }^{22}$. Uma vez mais o magistério de Piero Calamandrei:}

A querela de nulidade, na realidade, não foi abolida: ela, genial criação do nosso direito estatutário, deixou no sistema recursal traços duráveis e profundos que permitem, reconhecendo e aproximando os elementos deste instituto hoje dispersos em normas heterogêneas e distintas, reencontrar e reconstruir a sua fisionomia: como fazem os arqueólogos, que unindo fragmentos de diferentes tarefas de escavação, com paciência, conseguem reviver a estátua ${ }^{23}$.

\section{Nesse diapasão, o Superior Tribunal de Justiça ${ }^{24}$ e o Supremo Tribunal Federal reconheceram prevalecer no direito brasi-}

22 "A decisão judicial transitada em julgado desconforme com a Constituição padece do vício da inconstitucionalidade que, nos mais diversos ordenamentos jurídicos, lhe impõe a nulidade". Humberto Theodoro Jr. \& Juliana Cordeiro de Faria, A coisa julgada inconstitucional e os instrumentos processuais para o seu controle, em Coisa julgada inconstitucional, 96 ( $2^{\mathrm{a}}$ ed. ver. e ampl., Carlos Valder do Nascimento, coord., América Jurídica, Rio de Janeiro, 2003).

23 Tradução livre. Na língua original: "La querela di nulità in realtà non è stata abolita: essa, geniale creazioni del nostro dirrito statutario, há lasciato nel sistema dei mezzi di impugnazione tracde durevoli e profonde, Che permettono, riconoscendo e riaccostando gli elementi di questo istituto oggi dispersi in nome eterogenee e distanti, di ritrovare e di recostruire la sua fisionomia:come fanno gli archeologi, Che mettendo insieme frammenti recuperati da diversi compi di scavo, riescono com pazienza a far rivivere la statua". Piero Calamandrei, Sopravvivenza della querella di nullità nel processo civile vigente, VI Rivista di Diritto Processuale, 112-128 (Casa Editrice Dottore Antonio Milani, CEDAM, Padova, 1951).

24 Veja-se o excerto do acórdão do Superior Tribunal de Justiça: "I. A tese da querella nullitatis persiste no direito positivo brasileiro, o que implica dizer que a nulidade da sentença pode ser declarada em ação declaratória de nulidade, eis que, sem a citação, o processo, vale falar, a relação jurídica processual, não se constitui, nem validamente se desenvolve. Nem, por outro lado, a sentença transita em julgado, podendo, a qualquer tempo, ser declarada nula, em ação com esse objetivo, ou em embargos à execução, se for o caso. II. Recurso não conhecido". Brasil, Superior Tribunal de Justiça, STJ, Recurso Especial 12.586, REsp 12586. Relator ministro Waldemar Zveiter. Julgamento 4 de novembro de 1991. Disponível em: https://ww2.stj.jus.br/processo/pesquisa/?tipoPesquisa=tipo Pesquisa NumeroRegistro\&termo $=199100142026 \&$ totalRegistrosPorPagina $=40 \&$ aplicacao=processos.ea. Sobre a querella nullitatis, consultar: Ovídio Araújo Baptista da Silva, Sobrevivência da querela nullitatis, 333 Revista Forense, 115-122 (janeiro-março, 1996). Alexander dos Santos Macedo, Da querela nullitatis. Sua subsistência no direito 
leiro ação de impugnação autônoma, visando a um iudicium rescindens de sententia contaminada por invalidade insuprível. Obtida a procedência do pedido, poderá o querelante colher nova prolação do meritum causae ${ }^{25}$.

A admissibilidade da actio nullitatis no ordenamento jurídico pátrio reforça-se após a edição da Medida Provisória 2.180-35, de 24 de agosto de 2001, que acresceu parágrafo único ao artigo 741 ao Código de Processo Civil explicitando a coisa julgada inconstitucional como hipótese de inexigibilidade do título judicial ${ }^{26}$.

Da dicção teleológica da ratio extrai-se ser ele igualmente inexigível se sua validez não restou reconhecida, também, pela instância inferior, em razão do sistema difuso de controle.

Desse modo, a res judicata será destituída de força quando esbater-se com regramento superior e/ou contrariar decisão exarada pelas Cortes de Justiça - Excelsa ou a quo — não se sujeitando a prazos prescricionais ou decadenciais para sua arguição ${ }^{27}$.

\section{As ações cautelares}

Por derradeiro, cabível, outrossim, na esfera cível, a suspensão do julgado rescindendo mediante procedimento cautelar. Ao

brasileiro ( $3^{\mathrm{a}}$ ed., Lumen Juris, Rio de Janeiro, 2005).

25 Moacyr Amaral Santos, Primeiras linhas de direito processual civil, vol. 3, 443 (4 $4^{\mathrm{a}}$ ed., Saraiva, São Paulo, 1970).

26 Expressis verbis: "Art. 741 omissis: Parágrafo único. Para efeito do disposto no inciso II deste artigo, considera-se também inexigível o título judicial fundado em lei ou ato normativo declarados inconstitucionais pelo Supremo Tribunal Federal ou em aplicação ou interpretação tidas por incompatíveis com a Constituição Federal”. Brasil, Presidente da República, Medida Provisória 2.180-35, MPV 2180-35, 24 de agosto de 2001, acresce e altera dispositivos das Leis 8.437, de 30 de junho de 1992, 9.028, de 12 de abril de 1995, 9.494, de 10 de setembro de 1997, 7.347, de 24 de julho de 1985, 8.429, de 2 de junho de 1992, 9.704, de 17 de novembro de 1998, do Decreto-Lei 5.452, de 1 de maio de 1943, das Leis 5.869 , de 11 de janeiro de 1973 , e 4.348 , de 26 de junho de 1964, e dá outras providências, Publicado no Diário Oficial da União, DOU, 27 de agosto de 2001. Disponível em: http:// www.trtsp.jus.br/geral/tribunal2/LEGIS/MPV/2180_01.html

27 A decisão judicial, na qualidade de ato jurídico-público, submete-se ao controle da constitucionalidade. A coisa julgada desconforme à Constituição é, portanto, ato nulo, razão pela qual, "não produz efeitos desde a origem, mas é necessária declaração de inconstitucionalidade ou decisão de não aplicação", conforme ressalta Jorge Miranda. Jorge Miranda, Manual de direito constitucional: introdução à teoria da constituição, 316 ( $2^{\mathrm{a}}$ ed., Coimbra Editora, Lisboa, 1988). 
enfrentarem o assunto, doutrinadores e Tribunais admitem a mitigação do artigo 489 do Código de Processo Civil, quando estiverem presentes os pressupostos do fumus boni iuris e do periculum in mora.

Atenuando a rigidez da legis, gradativamente passou-se a aceitar a possibilidade do ajuizamento de ações cautelares preparatórias ou incidentais à rescisória para obstar julgado que se intenta quebrantar, de maneira a viabilizar a suspensão dos efeitos executórios do decisum por intermédio do poder geral de cautela.

Outra não tem sido a exegese do Pretório Excelso que, por maioria, referendou medida liminar concedida pelo Ministro Nelson Jobim na Petição 1.347/SP, atribuindo efeito suspensivo à ação rescisória e, consequentemente, suspendendo os efeitos da sentença rescindenda.

\section{A revisão criminal}

$\mathrm{Na}$ seara penal, a sententia iudicis com trânsito em julgado aperfeiçoado é refutada por meio da Revisão Criminal. A legislação vislumbra sua interposição nos artigos. 621 a 631 do CPP e, à semelhança da motivação cível, estatui a possibilidade de reverem-se processos findos quando a condenação for contrária ao texto expresso da lei; ou seja, quando inobservar o devido processo legal, garantia magna, revestida de fundamentalidade e clausulada com pétrea ${ }^{28}$.

A propósito dos julgados inconstitucionais, manifesta-se Paulo Otero:

28 Litteris: "Art. 621. A revisão dos processos findos será admitida: quando a sentença condenatória for contrária ao texto expresso da lei penal ou à evidência dos autos; II. quando a sentença; condenatória se fundar em depoimentos, exames ou documentos comprovadamente falsos; III. quando, após a sentença, se descobrirem novas provas de inocência do condenado ou de circunstâncias que determine ou autorize diminuição especial da pena". Brasil, Decreto-Lei 3.689, 3 de outubro de 1941, Código de Processo Penal, CPP, Diário Oficial da União, DOU, 13 de outubro de 1941 e retificado em 24 de de outubro de 1941. Disponível em: http://www.planalto.gov.br/ccivil_03/Decreto-Lei/ Del3689.htm 
Os actos jurisdicionais, isto é, que sejam praticados por um juiz no exercício das suas funções obedecendo aos requisitos formais e processuais mínimos, que violem direitos absolutos ou os demais direitos fundamentais e a essência dos princípios integrantes da Constituição material não são actos inexistentes, meras aparências, antes se assumem como verdadeiras decisões jurídicas inconstitucionai ${ }^{29}$.

\section{Sob esse prisma, José Joaquim Gomes Canotilho y Vital} Moreira sustentam que concretizada a inconstitucionalidade, há de ser objetada por recurso:

A verdade, porém, é que podem configurar-se hipóteses em que uma decisão judicial ofende diretamente a Constituição, podendo entender-se não serem meios de defesa bastantes os recursos ordinários que caibam no caso (se é que a decisão em causa ainda admite recurso). É por isso que alguns ordenamentos constitucionais prevêm a possibilidade de recursos para $o$ TC [Tribunal Constitucional] nessas hipóteses, sobretudo quando se trata de casos respeitantes a direitos fundamentais (é o caso do verfassung sbescwerde alemão e do recurso de amparo mexicano e espanhol) ${ }^{30}$.

Ora, incongruente seria a segurança jurídica servir de obstáculo para impedir a revisão de julgado desprovido de validade hierárquico-normativa, sob pena de frustrar o ideário de Justiça, ínsito no provimento jurisdicional. Nesse contexto, sua relativização apresenta-se como forma de corrigir distorções na aplicação da lei, bem assim a anarquia judicante ${ }^{31}$.

29 Paulo Manuel Cunha da Costa Otero, Ensaio sobre o caso julgado inconstitucional, 64 (LEX Edições Jurídicas, Lisboa, 1993).

30 José Joaquim Gomes Canotilho \& Vital Moreira, Fundamentos da constituição, 259 (Coimbra Editora, Coimbra, 1991).

31 Anita Pereira do Carmo, Como relativizar a coisa julgada? Discussões e propostas (Dissertação de Mestrado, Faculdade de Ciências Humanas da Fundação Mineira de Educação e Cultura, FUMEC, Belo Horizonte, 2007). Disponível em: http://www.fch.fumec.br/ cursos/mestrado/dissertacoes/anita_carmo.pdf 
CONCLUSÃo

Tal como colocado, plenamente autorizado ao Poder Judiciário relativizar a res judicata conspurcadora, de forma criteriosa $\mathrm{e}$ com equilíbrio, dentro dos parâmetros de controle e desmistificando resistências conservadoras, sob o apanágio de sufragar valores mais elevados resguardados pelo Estado Democrático de Direito. Nulo é, pois, o provimento iudicis que não se adequar à Lex Fundamentalis, porquanto impregnado de carga lesiva ao ordenamento legal ${ }^{32}$.

Conclamando os juristas acerca da necessidade de inovação do instituto, afirma Cândido Rangel Dinamarco:

É inconstitucional a leitura clássica da garantia da coisa julgada, ou seja, sua leitura com a crença de que ela fosse algo absoluto e, como era hábito dizer, capaz de fazer do preto, branco e do quadrado, redondo. $A$ irrecorribilidade de uma sentença não apaga a inconstitucionalidade daqueles resultados substanciais política ou socialmente ilegítimos, que a Constituição repudia. Daí a propriedade e a legitimidade sistemática da locução, aparentemente paradoxal, coisa julgada inconstitucional ${ }^{33}$.

Indubitável deverem as decisões da Judicatura exaradas em confronto com o arcabouço jurídico máximo serem rechaçadas ${ }^{34}$. E nesse conspecto, pronunciamento judicial que incorra

32 A respeito, posiciona-se Carlos Valder do Nascimento: “(...) o acatamento da coisa julgada, corolário da segurança jurídica, não é colocado em xeque pela probabilidade de uma pretensão de nulidade contra o julgamento violador de preceito constitucional. Primeiro, porque seu alcance sofre limitações no seu aspecto subjetivo, com a possibilidade de manuseio da rescisória, para desconstituição do julgado. Segundo, porque presente, nesses casos, os pressupostos da relatividade inerentes à natureza das coisas. De fato, inexiste a pretensa impermeabilidade que deseja se atribuir às decisões emanadas do Poder Judiciário.

Tentam, os que assim pensam, travestir a coisa julgada da argamassa de intocabilidade, tentando revelar sua faceta de cunho absoluto, que não resiste a uma análise mais aprofundada dentro do cenário da principiologia lastreada no constitucionalismo". Carlos Valder do Nascimento, Coisa julgada inconstitucional, em Coisa julgada inconstitucional, 12 ( $2^{\mathrm{a}}$ ed. ver. e ampl., Carlos Valder do Nascimento, coord., América Jurídica, Rio de Janeiro, 2003).

33 Cândido Rangel Dinamarco, Relativizar a coisa julgada material, 358 Revista Forense, 25 (nov./dez. 2001). Disponível em: http://www.processocivil.net/novastendencias/relativizacao.pdf

34 É a lição de Paulo Otero: "No entanto, em paralelo a tais casos de decisões judiciais inconstitucionais, importa reconhecer que podem existir decisões judiciais cujo conteúdo ofenda directa e imediatamente a Constituição sem interposição de qualquer norma. 


\section{em conflito com os postulados supremos merece enfrentamento, seja ele pendente de recurso ou não mais. $\mathrm{O}$ modo acertado e legítimo para dirimi-lo é a ponderação de valores envolvidos no caso concreto. Impõe-se exercitar juízo de proporcionalidade ${ }^{35}$ e razoabilidade ${ }^{36}$, oportunidade na qual o juiz ponderando-os,}

(...) A idéia da defesa da segurança e certeza da ordem jurídica constituem princípios fundamentadores de uma solução tendente a limitar ou mesmo excluir a relevância da inconstitucionalidade como factor autônomo de destruição do caso julgado. No entanto, se o princípio da constitucionalidade determina a insusceptibilidade de qualquer acto normativo inconstitucional se consolidar na ordem jurídica, tal facto poderá fundamentar a possibilidade, senão mesmo a exigência, de destruição do caso julgado desconforme com a Constituição". Paulo Manuel Cunha da Costa Otero, Ensaio sobre o caso julgado inconstitucional, 66, 93 (LEX Edições Jurídicas, Lisboa, 1993).

35 Pressupõe o princípio da proporcionalidade, o arbítrio dos interesses em disputa sob uma tríplice dimensão; adequação, necessidade e proporcionalidade em sentido estrito, de maneira a atender os seguintes imperativos: (a) a restrição a cada um dos princípios deve ser idônea para garantir a sobrevivência do outro; (b) a restrição deve ser a menor possível para a proteção do princípio contraposto e (c) o benefício logrado com a restrição a um princípio tem de compensar o grau de sacrifício imposto ao princípio antagônico. Robert Alexy agrega um quarto elemento ao postulado, a saber: a adequada motivação como requisito indispensável para a legitimação das decisões judiciais que fazem uso da ponderação, defendendo que, por meio delas, o julgador conquiste a adesão racional do público em geral, possibilitando aferir sua razoabilidade e sua compatibilidade com a axiologia constitucional e com os valores humanitários sintetizados na ideia de dignidade da pessoa humana. Robert Alexy, Teoria dos direitos fundamentais, 167 et seq ( $2^{\mathrm{a}}$ ed., Malheiros Editores, São Paulo, 2011). Ver, também, Esdras Boccato, Modulação dos Efeitos temporais da declaração de inconstitucionalidade. Ponderação, subsunção e dosimetria, 53-120 (Dissertação apresentada à Faculdade de Direito da Universidade de São Paulo para a obtenção do título de Mestre em Direito do Estado. Orientação Prof. Dr. Roger Stiefelmann Leal, 2013).

36 Comumente assemelhadas, proporcionalidade e razoabilidade são conceitos distintos, com conteúdos diversos. O primeiro nasce do direito europeu continental e ganha sistematização e desenvolvimento com a jurisprudência do Tribunal Constitucional alemão. Já o segundo, tem origem e desenvolvimento na common law, e adquire relevância na jurisprudência da Suprema Corte norte-americana. Aharon Barak define a razoabilidade como "um conceito notoriamente vago, como uma categoria de referência ilusória. $\mathrm{O}$ único caminho para avançar na discussão sobre a substância da razoabilidade é reconhecê-la não como um conceito físico ou metafísico, e sim, normativo. Razoabilidade significa identificar considerações relevantes e então equilibrá-las de acordo com seus pesos. Ao final, razoabilidade é um processo evolutivo, não um processo descritivo. Ela não é apenas racionalidade. Uma decisão é razoável se ela foi construída por ponderação de considerações necessárias, incluindo valores fundamentais em geral e direitos humanos em particular. Nada é razoável 'em si'” (tradução livre). Aharon Barak, The Judge in a Democracy, 466-467 (Princeton University Press, Princeton, 2006). Na língua original: "(...) the concept of reasonableness is notoriously vague. It is a "category of illusory reference'. The only way to further the discussion about the substance of reasonableness is to recognize that reasonableness is neither a physical nor a metaphysical concept but a normative one. Reasonableness means that one identifies the relevant considerations and the balances them according to their weight. Indeed, reasonableness is an evaluative process, not a descriptive process. It is not a concept that is defined by deductive logic. It is not merely rationality. A decision is reasonable if it was made by weighing the necessary considerations, including fundamental values in general and human rights in particular. Nothing is reasonable 'in itself'". 


\section{efetuará a aferição do decisum verticalmente incongruente com a Carta Política ${ }^{37}$. \\ Uma vez prolatado o iuris dicere pelo magistrado, na qualida- de de ato jurídico-público submeter-se-á à aferição da verticali- dade fundamentadora e, se desconforme for à Lei Maior, será o decisum nulo, ou seja, não produzirá efeitos desde a origem; pois tal qual sustenta Pontes de Miranda, "o nulo não tem eficácia"38.}

Para um maior desenvolvimento do tema, consultar: Juliane Stival, O controle judicial da sanção disciplinar militar à luz do princípio da proporcionalidade e os princípios da hierarquia e disciplina, 47 et seq. (Dissertação apresentada como requisito para a obtenção de grau de Mestre pelo Programa de Pós-Graduação em Direito da Faculdade de Direito da Pontifícia Universidade Católica do Rio Grande do Sul. Orientador: Prof. Dr. Juarez Freitas, Porto Alegre, 2013).

37 "Podem ser consideradas como sentenças injustas, ofensivas aos princípios da legalidade e da moralidade e atentatórias à Constituição, por exemplo, as seguintes: (...) e) a reconhecedora da existência de um fato que não está adequado à realidade (...). Estes e outros são exemplos de sentença que nunca terão força de coisa julgada e que poderão, a qualquer tempo, ser desconstituída, porque praticam agressão ao regime democrático no seu âmago mais consistente que é a garantia da moralidade, da legalidade, do respeito à Constituição e da entrega da justiça”. José Augusto Delgado, Efeitos da coisa julgada e os princípios constitucionais, em Coisa julgada inconstitucional, 101-103 ( $2^{\mathrm{a}}$ ed. ver. e ampl., Carlos Valder do Nascimento, coord, América Jurídica, Rio de Janeiro, 2003).

Colacione-se a propósito do tema, avaliação doutrinária acerca da carência da motivação extrínseca/intrínseca das decisões judiciais. "Em última análise, trata-se de garantir às partes o direito de verem examinadas pelo órgão julgador as questões, de fato e de direito, que houverem suscitado, reclamando do juiz a consideração atenta dos argumentos e provas trazidos.

A questão liga-se à da motivação da sentença, entre cujas justificativas políticas também se insere o direito de as partes verem apreciados seus argumentos e provas, direito esse a ser exatamente aferido na motivação.

Por isso salientou-se que a motivação da decisão se torna o melhor ponto de referência para verificar se a atividade das partes foi efetivamente respeitada. É que é na configuração do juízo de fato que mais relevante se torna o dever de motivar, porquanto é no campo da valoração das provas que se deixa ao juiz margem maior de discricionariedade.

Resulta daí que a carência de motivação pode revestir-se de diversos aspectos, apresentando-se em três situações diversas: a) quando o juiz omite as razões de seu convencimento; b) quando as tenha indicado incorrendo em evidente erro lógico-jurídico, de modo que as premissas de que extraiu sua decisão possam ser consideradas sicut non essent - carência de motivação intrínseca; ou, c) quando, embora no seu contexto a sentença pareça motivada, tenha omitido o exame de um fato decisivo para o juízo que leve a crer que, se o juiz o tivesse examinado, teria alcançado uma decisão diversa - carência de motivação extrínseca (Bellavista).

Especificamente no que se refere à carência de motivação extrínseca, que se caracteriza quando o juiz deixa de apreciar provas ou questões de fato ou de direito decisivas para $o$ julgamento, os tribunais têm fulminado a sentença, por insanável nulidade" (sem negritas no original). Ada Pellegrini Grinover, Antonio Scarance Fernandes \& Antonio Magalhães Gomes Filho, As nulidades no processo penal, 143-144 ( $9^{\mathrm{a}}$ ed. rev. atual. e ampl., Editora Revista dos Tribunais, RT, São Paulo, 2006).

38 Pontes de Miranda, Comentários ao Código de Processo Civil, tomo V, 111 ( $3^{\mathrm{a}}$ ed., Forense, Rio de Janeiro, 1997). 
"Mas é necessária declaração de inconstitucionalidade ou decisão de não aplicação", na lição de Jorge Miranda ${ }^{39}$, a fim de refutarem-se os efeitos dela decorrentes ${ }^{40}$. Como consequência, o desfazimento da res judicata originará uma decisão constitutiva negativa ${ }^{41}$.

No Brasil, o controle incidental caracteriza-se pela permissão conferida a qualquer juiz ou tribunal para realizar, na lide $s u b$ examine, a análise da concordância da lei infraconstitucional diante da Lex Fundamental, bem assim, da pertinência dos atos emanados de autoridade judiciária frente a ela. Trata-se de mecanismo inerente ao sistema dos checks and balances ${ }^{42}$.

Sem embargo de hodiernamente admitirem-se mitigações às sanções decorrentes do vício de inconstitucionalidade no controle abstrato, nomeadamente após a edição da Lei 9.868/99, atenuando-se os efeitos retro-operantes da norma invalidada; tratando-se de atos judiciais questionados por inobservância dos regramentos máximos, seu manejo sui generis enseja efeitos ex tunc e inter partes por incidir, invariavelmente, em lides concretas $^{43}$. Vale dizer, desarrazoada a modulação de efeitos

39 Jorge Miranda, Manual de direito constitucional: Introdução à teoria da constituição, 316 ( ${ }^{\mathrm{a}}$ ed., Coimbra Editora, Lisboa, 1988).

40 "A idéia que norteia o exame da natureza jurídica de revisão da coisa julgada restringe-se, exclusivamente, ao âmbito da sentença inconstitucional, perpassando também por esse crivo, as fraudulentas e manifestamente injustas. O objetivo é restabelecer o primado da Justiça, removendo-se os obstáculos que se antepõem à possibilidade efetiva de sua realização. Assim, devem ser corrigidos os vícios que a contaminam, utilizando-se dos meios processuais adequados à sua impugnação. (...)

A relação jurídica decorrente da ação autônoma de impugnação (declaratória) tem sua extinção decretada com a entrega da prestação jurisdicional. (...). De sorte que, nesse campo, a rediscussão não envolve pretensão de direito material, mas a essência da sentença que redundou na prestação satisfeita no plano jurisdicional". Carlos Valder do Nascimento, Por uma teoria da coisa julgada inconstitucional, 17 (Lumen Juris, Rio de Janeiro, 2005).

41 Ressona contundente a afirmação do Ministro José Delgado: “(...) não posso conceber o reconhecimento de força absoluta da coisa julgada quando ela atenta contra a moralidade, contra a legalidade, contra os princípios maiores da Constituição Federal e contra a realidade imposta pela natureza. Não posso aceitar, em sã consciência, que, em nome da segurança jurídica, a sentença viole a Constituição Federal (...)". José Augusto Delgado, Efeitos da coisa julgada e os princípios constitucionais (Palestra proferida no 20 de dezembro de 2000, no I Simpósio do Direito Público da Advocacia-Geral da União, AGU, 5 Região. Fortaleza).

42 Alexandre Freitas Câmara, Relativização da coisa julgada: enfoque crítico, 23 ( $2^{\mathrm{a}}$ ed., Fredie Didier Jr., org., JusPODIVM, Salvador, 2008).

43 Nestes termos, a modalidade de controle por via de exceção ou defesa apresenta-se como 
temporais em sede incidental porquanto o intento da declaração é desconstituir e nulificar os efeitos da res judicata viciada, de modo a assegurar um resultado útil à parte que a impugna.

Concluindo, dúvidas não restam de que ao conhecer os atos incongruentes com a Norma Normarum, aí incluídas as decisões judiciais transitadas em julgado, estabelece a Judicatura os limites da res publicam. O descumprimento de preceitos jurídicos superiores, mormente pelo órgão que deveria fiançá-los, desprestigia a força normativa da Constituição e da própria legitimidade do regime implementado pelo Legislador Originário.

Afinal, quando o Estado de Direito proclamou a autoridade do Poder Judiciário to decide on the rights of individuals, na histórica decisão de John Marshall, fez-lhe o pilar de sustentação do sistema democrático. Por isso, sua atuação há de pautar-se consoante o ethos público, competindo-lhe formular pretensões cognitivas que explicitem uma atuação comprometida com os valores universais de justiça e prestigiem o Contrato políticosocial que jurou respeitar e fazer cumprir. 


\section{BIBLIOGRAFIA}

\section{Livros}

Alessi, Renato, Sistema instituzionale del diritto amministratìvo italiano (Giuffrè, Milano, 1953).

Alexy, Robert, Teoria dos direitos fundamentais ( $2^{\mathrm{a}}$ ed., Malheiros Editores, São Paulo, 2011).

Barak, Aharon, The Judge in a Democracy (Princeton University Press, Princeton, 2006).

Barbosa Moreira, José Carlos, org., Comentários ao Código de Processo Civil, vol. 5 (10 a ed., Forense, Rio de Janeiro, 2002).

Câmara, Alexandre Freitas, Relativização da coisa julgada: enfoque crítico ( $2^{\mathrm{a}}$ ed., Fredie Didier Jr., org., JusPODIVM, Salvador, 2008).

Canotilho, José Joaquim Gomes \& Moreira, Vital, Fundamentos da constituição (Coimbra Editora, Coimbra, 1991).

Espínola, Eduardo \& Espínola Filho, Eduardo, A lei de introdução ao Código Civil

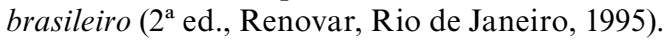

Grinover, Ada Pellegrini; Fernandes, Antonio Scarance \& Gomes Filho, Antonio Magalhães, As nulidades no processo penal $\left(9^{\mathrm{a}} \mathrm{ed}\right.$. rev. atual. e ampl., Editora Revista dos Tribunais, RT, São Paulo, 2006).

Liebman, Enrico Túlio, Manual de direito processual civil (Forense, Rio de Janeiro, 1984).

Macedo, Alexander dos Santos, Da querela nullitatis. Sua subsistência no direito brasileiro ( $3^{\text {a }}$ ed., Lumen Juris, Rio de Janeiro, 2005).

Miranda, Jorge, Contributo para uma teoria da inconstitucionalidade (Coimbra Editora, Coimbra, 1999).

Miranda, Jorge, Manual de direito constitucional: Introdução à teoria da constituição ( $2^{\mathrm{a}}$ ed., Coimbra Editora, Lisboa, 1988).

Miranda, Pontes de, Comentários ao Código de Processo Civil, tomo V ( $3^{\mathrm{a}}$ ed., Forense, Rio de Janeiro, 1997).

Nascimento, Carlos Valder do, Coisa julgada inconstitucional. Coisa julgada inconstitucional (Carlos Valder do Nascimento, coord., América Jurídica, Rio de Janeiro, 2003).

Nascimento, Carlos Valder do, Por uma teoria da coisa julgada inconstitucional (Lumen Juris, Rio de Janeiro, 2005).

Nery Jr., Nelson \& Nery, Rosa Maria de Andrade, Código de processo civil comentado e legislação extravagante $\left(10^{a}\right.$ ed. ver. ampl. e atual., Editora Revista dos Tribunais, RT, São Paulo, 2008).

Otero, Paulo Manuel Cunha da Costa, Ensaio sobre o caso julgado inconstitucional (LEX Edições Jurídicas, Lisboa, 1993).

Santos, Moacyr Amaral, Primeiras linhas de direito processual civil, vol. 3 (4⿳⺈冂⿲二丨匕口 ed, 
Saraiva, São Paulo, 1970).

Silva, Ovídio Araújo Baptista da, Curso de processo civil: processo de conhecimento, vol. 1 (6 ${ }^{\mathrm{a}}$ ed. rev. e atual., Editora Revista dos Tribunais, RT, São Paulo, 2002).

Talamini, Eduardo, Coisa julgada e sua revisão (Editora Revista dos Tribunais, São Paulo, 2005).

Theodoro Jr., Humberto \& Faria, Juliana Cordeiro de, A coisa julgada inconstitucional e os instrumentos processuais para o seu controle, em Coisa julgada inconstitucional ( $2^{\mathrm{a}}$ ed. ver. e ampl., Carlos Valder do Nascimento, coord., América Jurídica, Rio de Janeiro, 2003).

Wambier, Teresa Arruda Alvim \& Medina, José Miguel Garcia, $O$ dogma da coisa julgada: hipóteses de relativização (Editora Revista dos Tribunais, RT, São Paulo, 2003).

\section{Colaborações em obras coletivas}

Calamandrei, Piero, Vicios de la sentencia y medios de gravamen, em Estudios sobre el proceso civil (Ediciones Jurídicas Europa-América, EJEA, Buenos Aires, 1961).

Delgado, José Augusto, Efeitos da coisa julgada e os princípios constitucionais, em Coisa julgada inconstitucional ( $2^{\mathrm{a}}$ ed. ver. e ampl., Carlos Valder do Nascimento, coord, América Jurídica, Rio de Janeiro, 2003).

Nascimento, Carlos Valder do, Coisa julgada inconstitucional, em Coisa julgada inconstitucional ( $2^{\mathrm{a}}$ ed. ver. e ampl., Carlos Valder do Nascimento, coord., América Jurídica, Rio de Janeiro, 2003).

Jornais

Calamandrei, Piero, Sopravvivenza della querella di nullità nel processo civile vigente, VI Rivista di Diritto Processuale (Casa Editrice Dottore Antonio Milani, CEDAM, Padova, 1951).

Dinamarco, Cândido Rangel, Relativizar a coisa julgada material, 358 Revista Forense (nov./dez. 2001).

Silva, Ovídio Araújo Baptista da, Sobrevivência da querela nullitatis, 333 Revista Forense, 115-122 (janeiro-março, 1996).

Palestras, teses

Boccato, Esdras, Modulação dos Efeitos temporais da declaração de inconstitucionalidade. Ponderação, subsunção e dosimetria (Dissertação apresentada à Faculdade de Direito da Universidade de São Paulo para a obtenção do título de Mestre em Direito do Estado. Orientação Prof. Dr. Roger Stiefelmann Leal, 2013). 
Carmo, Anita Pereira do, Como relativizar a coisa julgada? Discussões e propostas (Dissertação de Mestrado, Faculdade de Ciências Humanas da Fundação Mineira de Educação e Cultura, FUMEC, Belo Horizonte, 2007. Disponível em: http://www.fch.fumec.br/cursos/mestrado/dissertacoes/anita_carmo.pdf

Delgado, José Augusto, Efeitos da coisa julgada e os princípios constitucionais ( $\mathrm{Pa}-$ lestra proferida no 20 de dezembro de 2000, no I Simpósio do Direito Público da Advocacia-Geral da União, AGU, 5 Região. Fortaleza).

Stival, Juliane, $O$ controle judicial da sanção disciplinar militar à luz do princípio da proporcionalidade e os princípios da hierarquia e disciplina (Dissertação apresentada como requisito para a obtenção de grau de Mestre pelo Programa de Pós-Graduação em Direito da Faculdade de Direito da Pontifícia Universidade Católica do Rio Grande do Sul, Orientador: Prof. Dr. Juarez Freitas, Porto Alegre, 2013).

\section{Normatividade internacional}

Alemanha, Zivilprozessordnung (Code of Civil Procedure as promulgated on 5 December 2005). Disponível em: http://www.gesetze-im-internet.de/zpo/ BJNR005330950.html, http://www.gesetze-im-internet.de/englisch_zpo/ englisch_zpo.html

Áustria, Zivilprozessordnung, Gesetz vom 1. August 1895. Disponível em: http:// www.wipo.int/wipolex/es/text.jsp?file_id=230305

Espanha, Constitución, 27 de diciembre de 1978, Boletín Oficial del Estado, BOE, 311, 29 de dezembro de 1978. Disponível em: http://www.boe.es/buscar/act. php?id=BOE-A-1978-31229

Espanha, Ley 1/2000, 7 de enero de 2000, Ley de Enjuiciamiento Civil, LEC, Boletín Oficial del Estado, BOE, 7, 08 de janeiro de 2000. Disponível em: https:// boe.es/buscar/act.php?id=BOE-A-2000-323

Espanha, Ley Orgánica 2/1979, de 3 de octubre, del Tribunal Constitucional, Boletín Oficial del Estado, BOE, 239, 5 de outubro de 1979. Disponível em: http://www.boe.es/buscar/act.php?id=BOE-A-1979-23709

França, Code de procédure civile. Disponível em: http://www.legifrance.gouv.fr/ affichCode.do?cidTexte=LEGITEXT000006070716

Itália, Codice di procedura civile. Disponível em: http://www.testolegge.com/ italia/procedura-civile

México, Constituição Política dos Estados Unidos Mexicanos, Diario Oficial de la Federación, 5 de fevereiro de 1917. Disponível em: http://www.diputados. gob.mx/LeyesBiblio/htm/1.htm

México, Ley de Amparo, reglamentaria de los artículos 103 y 107 de la Constitución Política de los Estados Unidos Mexicanos, Diario Oficial de la Federación, 2 de abril de 2013 y 14 de julio de 2014. Disponível em: http://leydeamparo.com.mx/, http://www.diputados.gob.mx/LeyesBiblio/ref/lamp/LAmp_orig_02abr13.pdf, http://www.diputados.gob.mx/LeyesBiblio/pdf/LAmp_140714.pdf 
Portugal, Código de Processo Civil, Lei 41/2013, 26 de junho, retificada pela Declaração de Retificação 36/2013, 12 de agosto - Aprova o Código de Processo Civil (revoga o Decreto-Lei 44129, de 28 de dezembro de 1961 / em vigor a partir de 1 de setembro de 2013). Disponível em: http://www.dgpj.mj.pt/sections/leis-dajustica/livro-iii-leis-civis-e/consolidacao-processo/codigo-de-processo-civil/

\section{Normatividade brasileira}

Brasil, Constituição da República Federativa do Brasil, CF, Brasília, 5 de outubro de 1988. Disponível em: http://www.planalto.gov.br/ccivil_03/Constituicao/ Constituicao.htm

Brasil, Decreto-Lei 3.689, 3 de outubro de 1941, Código de Processo Penal, CPP, Diário Oficial da União, DOU, 13 de outubro de 1941 e retificado em 24 de de outubro de 1941. Disponível em: http://www.planalto.gov.br/ccivil_03/ Decreto-Lei/Del3689.htm

Brasil, Decreto-Lei 4.657, de 1942, Lei de Introdução às normas do Direito Brasileiro (ao Código Civil), LICC, Diário Oficial da União, DOU, 4 de setembro de 1942. Disponível em: http://www.planalto.gov.br/ccivil_03/Decreto-Lei/ Del4707.htm

Brasil, Decreto-Lei 4.707, de 1942, dispõe sobre a vigência da Lei de Introdução ao Código Civil, LICC, Diário Oficial da União, DOU, 18 de setembro de 1942. Disponível em: http://www.planalto.gov.br/ccivil_03/Decreto-Lei/Del4707.htm

Brasil, Lei 5.869, 11 de janeiro de 1973, institui o Código de Processo Civil, CPC, Diário Oficial da União, DOU, 17 de janeiro de 1973 e republicado em 27 de julho de 2006. Disponível em: http://www.planalto.gov.br/ccivil_03/LEIS/ L5869compilada.htm

Brasil, Lei 9.868, 10 de novembro de 1999, dispõe sobre o processo e julgamento da ação direta de inconstitucionalidade e da ação declaratória de constitucionalidade perante o Supremo Tribunal Federal, Diário Oficial da União, DOU, 11 de novembro de 1999. Disponível em: https://www.planalto.gov.br/ ccivil_03/Leis/L9868.htm

Brasil, Lei 10.406/2002, institui o Código Civil, Diário Oficial da União, DOU, 11 de janeiro de 2002. Disponível em: http://www.planalto.gov.br/ccivil_03/ LEIS/2002/L10406.htm

\section{Jurisprudência brasileira}

Brasil, Superior Tribunal de Justiça, STJ, Recurso Especial 12.586, REsp 12586. Relator ministro Waldemar Zveiter. Julgamento 4 de novembro de 1991. Disponível em: https://ww2.stj.jus.br/processo/pesquisa/?tipoPesquisa=tipoPesquisa NumeroRegistro\&termo=199100142026\&totalRegistrosPorPagina $=40 \&$ aplicacao $=$ processos. ea

Brasil, Presidente da República, Medida Provisória 2.180-35, MPV2180-35, 24 de 
agosto de 2001, acresce e altera dispositivos das Leis 8.437, de 30 de junho de 1992, 9.028, de 12 de abril de 1995, 9.494, de 10 de setembro de 1997, 7.347, de 24 de julho de 1985, 8.429, de 2 de junho de 1992, 9.704, de 17 de novembro de 1998, do Decreto-Lei 5.452, de 1 de maio de 1943, das Leis 5.869, de 11 de janeiro de 1973, e 4.348, de 26 de junho de 1964, e dá outras providências, Publicado no Diário Oficial da União, DOU, 27 de agosto de 2001. Disponível em: http:// www.trtsp.jus.br/geral/tribunal2/LEGIS/MPV/2180_01.html

Brasil, Supremo Tribunal Federal, STF, Efeito Suspensivo em Ação Rescisória, Petição 1.347, PET 1347/SP. Relator ministro Nelson Jobim, 10 de setembro de 1997. Disponível em: http://www.stf.jus.br/arquivo/informativo/documento/ informativo84.htm

Brasil, Tribunal Regional do Trabalho SP 2 Região, TRTSP, Medida Provisória 2.180-35, MPV 2180-35, 24 de agosto de 2001, acresce e altera dispositivos das Leis 8.437, de 30 de junho de 1992, 9.028, de 12 de abril de 1995, 9.494, de 10 de setembro de 1997, 7.347, de 24 de julho de 1985, 8.429, de 2 de junho de 1992, 9.704, de 17 de novembro de 1998, do Decreto-Lei 5.452, de 1 de maio de 1943, das Leis 5.869, de 11 de janeiro de 1973, e 4.348, de 26 de junho de 1964, e dá outras providências, Publicado no Diário Oficial da União, DOU, 27 de agosto de 2001. Disponível em: http://www.trtsp.jus.br/geral/tribunal2/ LEGIS/MPV/2180_01.html

\section{Casos internacionais}

United States, Supreme Court of the United States, Marbury v. Madison case, 5 U.S. 137 (1803), Chief Justice John Marshall. Disponível em: https://supreme. justia.com/cases/federal/us/5/137/case.html 